\title{
Enteric Parasitic Infections in HIV/AIDS Patients Before and After the Highly Active Antiretroviral Therapy
}

\author{
Tatiana Paschoalette Rodrigues Bachur ${ }^{1}$, Josias Martins Vale ${ }^{1}$, Ivo Castelo Branco Coêlho ${ }^{1}$, \\ Telma Régia Bezerra Sales de Queiroz ${ }^{2}$ and Cristina de Souza Chaves ${ }^{1}$ \\ ${ }^{1}$ Department of Pathology and Legal Medicine - Medical School - Federal University of Ceará; \\ ${ }^{2}$ São José Infectious Diseases Hospital; Fortaleza, CE, Brazil
}

\begin{abstract}
Enteroparasites are related to gastrointestinal alterations among patients with HIV/AIDS, some causing severe manifestations in the period before the institution of the highly active antiretroviral therapy (HAART). The prevalence of enteroparasitoses in patients with HIV/AIDS seen at two hospitals in Ceará, Brazil, was compared in the pre-HAART (Group 1; $n=482$ ) and HAART (Group 2; $n=100$ ) eras. Fecal parasitologic examinations (FPE) were performed using the direct, Lutz, Baermann-Moraes and modified Ziehl-Neelsen methods. The following parasites were detected in Groups 1 and 2, respectively: Strongyloides stercoralis $-30.1 \%$ and $11 \%(p<0.0001)$, Ascaris lumbricoides $-15.6 \%$ and $2 \%(p<0.0001)$, hookworms $-13.7 \%$ and $2 \%(p<0.0001)$, Trichuris trichiura $-13.1 \%$ and $1 \%(p<0.0001)$, Hymenolepis nana - 0 and $1 \%(p=0.1718)$, Giardia duodenalis $-7.9 \%$ and $1 \%(p=0.0076)$, Entamoeba histolytica/ dispar $-3.3 \%$ and $1 \%(p=0.3301)$, Isospora belli $-4.8 \%$ and $1 \%(p=0.0993)$, Cryptosporidium sp. $-8.1 \%$ and $0(p=$ $\mathbf{0 . 0 0 0 7 )}$, and non-pathogenic protozoans as well. There was a significant reduction in the prevalence of enteroparasites between the eras $(63.9 \%$ to $24 \%$; $<<0.0001)$. In the HAART era, the following observations were made: greater frequency of enteroparasites in patients without antiretroviral therapy $(p=0.0575)$, as in those with AIDS $(p=0.08)$, and diarrhea (36\% of the patients); lack of association with positive FPE ( $p=0.626)$; and non-detection of Cryptosporidium sp. Strongyloides stercoralis showed an elevated prevalence in the two eras and was more frequent in men $(32.41 \%)$ than women $(19.04 \%)$ of Group $1(p=0.018)$, a finding suggesting the transmission of the helminth through sodomy. The advent of the HAART modified the profile of opportunistic infections, including parasites, probably due to the reconstitution of cellular immunity and the direct action of HAART on the parasites.

Key-Words: Enteric parasitic infections, HIV, AIDS, antiretroviral therapy.
\end{abstract}

Since the discovery of acquired immunodeficiency syndrome (AIDS), many studies demonstrated that intestinal parasites were frequently associated with pictures of severe diarrhea in patients with HIV, in developed as well as developing countries [1-7]. Enteroparasites such as Cryptosporidium sp., Isospora belli and Strongyloides stercoralis, among others, are related to gastrointestinal changes among patients with the virus, some occurring with an elevated prevalence in these patients in the years preceding the introduction of highly active antiretroviral therapy (HAART) [8-10].

Among immunocompromised patients, for example those with HIV, certain risk behaviors, such as homosexual relations and practicing oro-anal sex, can exacerbate the possibility of acquiring some intestinal parasitoses such as giardiasis, cryptosporidiosis and strongyloidiasis, where the symptomatic pictures are more serious than those of

Received on 5 December 2007; revised 4 April 2008.

Address for correspondence: Dr. Tatiana Paschoalette Rodrigues Bachur. Departamento de Patologia e Medicina Legal, Setor de Parasitologia, Faculdade de Medicina, Universidade Federal do Ceará. Rua Monsenhor Furtado, SN, Rodolfo Teófilo. Zip code: 60 441-750. Fortaleza, Ceará, Brazil. Telephones: 853366 8310/85 3366 8311. Fax: 8533668300 E-mail: tatiana@bachur.com.br; tatianabachur@gmail.com.

Financial support: Conselho Nacional de Desenvolvimento Científico e Tecnológico $(\mathrm{CNPq})$ and Coordenação de Aperfeiçoamento de Pessoal de Nível Superior (CAPES) through the Postgraduate Program in Pathology at the Federal University of Ceará.

The Brazilian Journal of Infectious Diseases 2008;12(2):115-122. (C) 2008 by The Brazilian Journal of Infectious Diseases and Contexto Publishing. All rights reserved. individuals with a non-compromised immune system [11,12]. Keystone and et al. (1980) [13] demonstrated, even before the discovery of AIDS, the greater risk for infection by intestinal parasites through these risk behaviors when comparing the prevalence of enteroparasites between groups of heterosexual and homosexual males.

With the progressive introduction of HAART starting in 1996, which helps in the control of HIV infection and in the reconstitution of the immune system of the patient, modifications have been observed in the morbi-mortality profile among HIV/AIDS patients, reflected in the reduced occurrence of opportunistic infections, including those caused by enteroparasites [14-17].

In view of the high frequency of intestinal parasitoses in our environment, many of them of opportunistic character, affecting seriously immunocompromised patients, the objective of this work was to determine and compare the prevalence of enteroparasites in patients with HIV/AIDS treated in periods before and after the advent of highly potent and effective antiretroviral therapy (HAART). These patients were seen in two referral hospitals of the state of Ceará, Brazil, and prevalence was correlated with clinical, laboratorial and epidemiological parameters.

\section{Material and Methods \\ Population Studied \\ Group 1}

Evaluated in a retrospective manner were data of 482 patients with HIV/AIDS seen at Hospital São José de Doenças Infecciosas (HSJ), Fortaleza-Ceará, Brazil, between January 
1990 and March 1995. The patients aged 18 years or older and had a fecal parasitologic examination (FPE). Informations obtained were: sex, age, categories of exposure to HIV and the results of the FPE.

\section{Group 2}

Prospectively, 100 patients with HIV/AIDS seen at HSJ and Hospital Universitário Walter Cantídio (HUWC), in the same city, between September 2005 and January 2007, were included; they were older than 18 years, agreed to participate in the study, responded to a standard questionnaire and had fecal specimens submitted for FPE. The following informations were collected from the questionnaires and their medical charts: socio-economic data, categories of exposure to HIV, antiretroviral therapy and gastrointestinal clinical manifestations at the moment of the FPE, use of various antiinfective medications up to 30 days before the fecal examination, results of CD4+ T lymphocyte counts and quantification of viral load carried out in the six-month period before or after the collection of the fecal specimen.

\section{Fecal Parasitologic Examination}

The specimens in both groups were processed in the Parasitology Sector of the Department of Pathology and Forensic Medicine of the School of Medicine, Federal University of Ceará (SP/DPML/FAMED/UFC). The patients of Group 1 (retrospectively), as well as those of Group 2 (prospectively) had at least one fresh fecal specimen examined by the following methods: direct, that is fresh and with Lugol's iodine; Lutz, also known as the Hoffmann, Pons and Janer or HPJ method, modified Baermann-Moraes and modified Ziehl-Neelsen staining [18]. They were read with a light microscope, including all of the fields of eight to ten slides per fecal specimen, where the slides were considered positive when showing cysts or oocysts of protozoans, as well as eggs or larvae of helminths.

\section{Complementary Tests}

CD4+ T lymphocyte counts of the patients of Group 2 were obtained by flow cytometry, and a quantification of viral load was determined using the sequential amplification of nucleic acids technique (NASBA), both performed by the Public Health Central Laboratory of Ceará (LACEN-CE). The results considered were those closest to the date of the FPE, obtained in the six-month interval before or after collection of the fecal specimen.

\footnotetext{
Statistical Analysis

Parametric and non-parametric methods were utilized in uni- and multivariate analyses. The maximum level of significance utilized for the statistical analyses was 5\%. The odds ratio (OR) was calculated for the parasites that showed significant reduction between the pre-HAART and HAART eras $(\mathrm{p}<0.05)$. The analyses were carried out using the program "Statistical Package for Social Sciences" (SPSS Inc., Chicago, IL), version 13.
}

Ethical Aspects

The project was evaluated by the Committee of Ethics in Research of HSJ and approved for the two hospitals. All the patients of Group 2 agreed to participate in the study and voluntarily signed an informed consent form.

\section{Results}

The Groups 1 (pre-HAART era) and 2 (HAART era) were composed of 482 and 100 patients with HIV/AIDS, respectively.

Comparatively, in the two groups the distribution per sex revealed a predominance of male cases (Group 1: 82.57\%; Group 2: $78 \%$ ), with male to female ratios of 4.74 and 3.55 in the preHAART and HAART eras, respectively $(\mathrm{p}=0.32$ ) (Table 1). However, between the men and women we obtained significant inverse results in the distribution per categories of exposure to HIV between the two eras. With regard to risk of contracting HIV through sexual relations, men who had sex with men (MSM), which represented 32.37\% of Group 1, represented $16 \%$ in Group 2 ( $\mathrm{p}=0.001)$, and men who had sex with women (MSW), which were $12.66 \%$ of Group 1, increased in proportion to $36 \%$ in Group $2(\mathrm{p}<0.001)$. The incidence of HIV remained stable among MSWM (Group $1=20.75 \%$ and Group 2 = 24\%; $\mathrm{p}=0.502$ ), and among the women, all in the HAART era acquired HIV in sexual relations with men (22\% of Group 2), where an increase of marginal significance was detected compared to the pre-HAART era (14.73\% of Group 1$)(\mathrm{p}=$ 0.074). In the current era, HAART era, the category of exposure to the virus by transfusion with blood and blood derivatives (TBBD) was not shown in the individuals included $(\mathrm{p}=0.056)$ (Table 1 ). The age varied from 18 to 70 years in Group 1, with a mean of $33.5 \pm 9.1$ and median of 32 years, while in Group 2, the variation was from 18 to 64 years, with a mean of $37.7 \pm 8.9$ and median of 36.5 years $(\mathrm{p}<0.001)$ (Table 1$)$.

The presence of enteroparasites was detected in $63.9 \%$ of the patients of Group 1, while in Group 2 this prevalence was $24 \%(p<0.0001)$ (Figure 1). A significant reduction in the prevalence of the helminths Strongyloides stercoralis, Ascaris lumbricoides, hookworms and Trichuris trichiura was observed in the HAART era in comparison with the preHAART era $(\mathrm{p}<0.0001)$. The cestoid Hymenolepis nana was found in one patient of Group 2. With respect to intestinal protozoans, a statistically significant reduction was seen in Giardia duodenalis $(\mathrm{p}=0.0076)$ and Cryptosporidium sp. $(\mathrm{p}=0.0007)$ between the eras; the latter had a prevalence of $8.1 \%$ in Group 1 but was not detected in Group 2. For the other protozoans, among the commensal and pathogenic ones (Endolimax nana, Iodamoeba butschlii, Isospora belli and Entamoeba histolytica/E. dispar), no statistically significant difference was observed between the groups (values of $\mathrm{p}>0.05$ ). Strongyloides stercoralis was the most frequent intestinal parasite in the two eras, with a prevalence of $30.1 \%$ and $11 \%$, respectively, occurring more often in men $(32.41 \%)$ than in women $(19.04 \%)$ of the pre-HAART era $(\mathrm{p}=$ 0.018). 


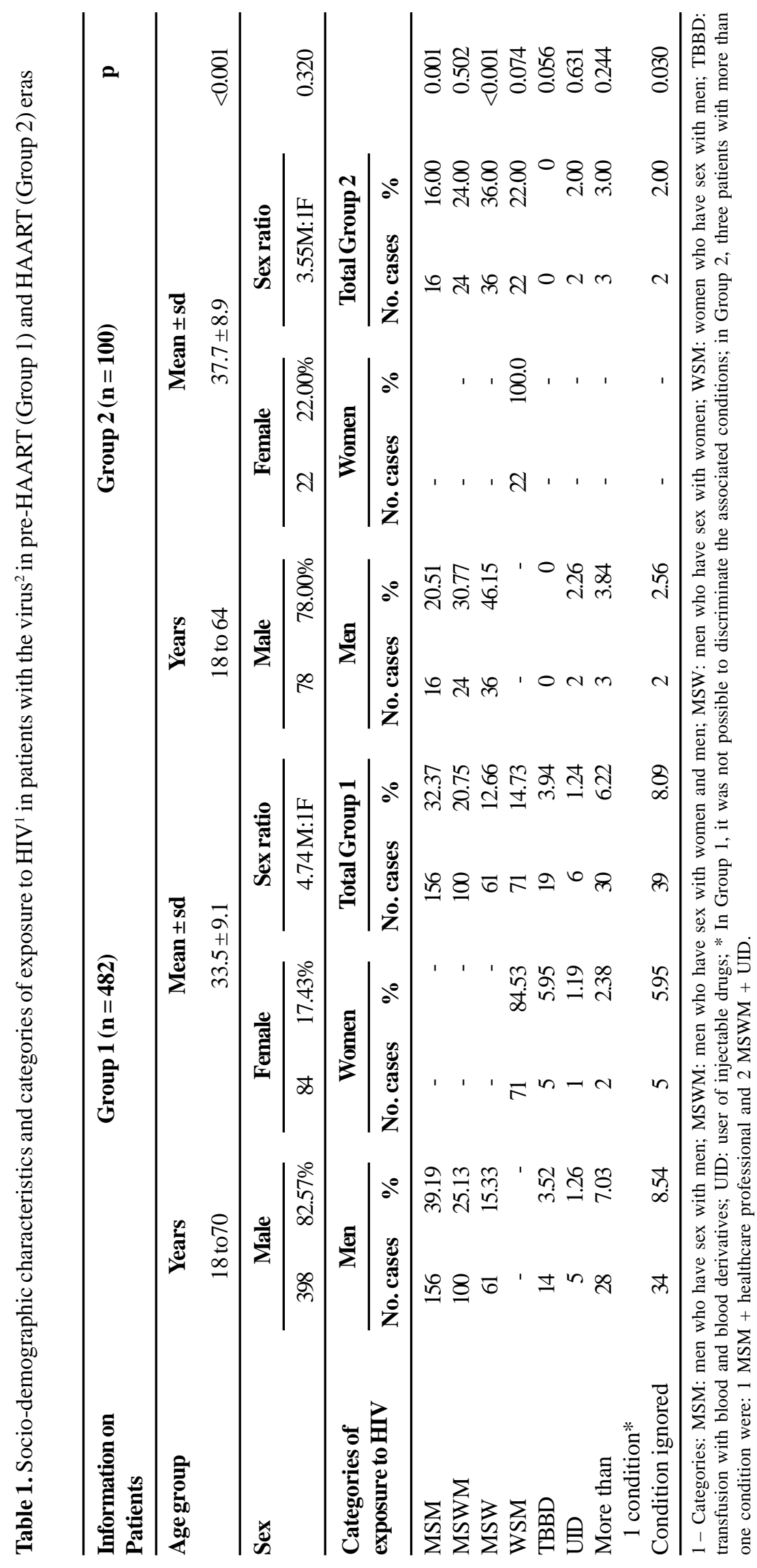


Table 2. Clinical findings of patients with HIV/AIDS seen in the HAART ${ }^{1}$ era at hospitals ${ }^{2}$ in Fortaleza-CE, Brazil

\begin{tabular}{|c|c|c|c|c|c|}
\hline \multirow{3}{*}{ Clinical findings } & \multicolumn{4}{|c|}{ Fecal parasitologic examination } & \multirow{3}{*}{$\mathbf{p}$} \\
\hline & \multicolumn{2}{|c|}{ Positive } & \multicolumn{2}{|c|}{ Negative } & \\
\hline & $\mathbf{N}$ & $\%$ & $\mathbf{N}$ & $\%$ & \\
\hline \multicolumn{6}{|l|}{ Use of HAART ${ }^{3}$} \\
\hline Patients using & 11 & 45.83 & 51 & 68.00 & \multirow[t]{3}{*}{0.058} \\
\hline Patients not using & 13 & 54.17 & 24 & 32.00 & \\
\hline Total & 24 & 100 & 75 & 100 & \\
\hline \multicolumn{6}{|l|}{ Presence of diarrhea } \\
\hline Yes & 10 & 41.67 & 26 & 34.21 & \multirow[t]{3}{*}{0.626} \\
\hline No & 14 & 58.33 & 50 & 65.79 & \\
\hline Total & 24 & 100 & 76 & 100 & \\
\hline \multicolumn{6}{|c|}{ CD4+ T lymphocyte count ${ }^{4}$} \\
\hline \multicolumn{6}{|c|}{ Stratification according to the criterion of MH-Brazil } \\
\hline$\leq 350$ cells $/ \mathrm{mm}^{3}$ & 17 & 73.90 & 48 & 69.50 & \multirow[t]{3}{*}{0.795} \\
\hline$>350$ cells $/ \mathrm{mm}^{3}$ & 6 & 26.10 & 21 & 30.50 & \\
\hline Total & 23 & 100 & 69 & 100 & \\
\hline \multicolumn{6}{|c|}{ Stratification according to the criterion of CDC-USA } \\
\hline$\leq 200$ cells $/ \mathrm{mm}^{3}$ & 14 & 60.90 & 26 & 37.70 & \multirow[t]{3}{*}{0.080} \\
\hline$>200$ cells $/ \mathrm{mm}^{3}$ & 9 & 39.10 & 43 & 62.30 & \\
\hline Total & 23 & 100 & 69 & 100 & \\
\hline \multicolumn{6}{|l|}{ Viral load ${ }^{5}$} \\
\hline Detectable & 6 & 26.10 & 26 & 39.40 & \multirow[t]{3}{*}{0.318} \\
\hline Undetectable & 17 & 73.90 & 40 & 60.60 & \\
\hline Total & 23 & 100 & 66 & 100 & \\
\hline
\end{tabular}

Table 3. Use of antiparasitic medication ${ }^{1}$ in relation to the results of the FPE of patients with HIV/AIDS ${ }^{2}$ seen in the HAART era $^{3}$ at hospitals ${ }^{4}$ in Fortaleza-CE, Brazil

\begin{tabular}{|c|c|c|c|c|c|}
\hline \multirow{3}{*}{$\begin{array}{l}\text { Medications with action on } \\
\text { parasites found }\end{array}$} & \multicolumn{4}{|c|}{ Parasites sensitive to medication utilized } & \multirow{3}{*}{$\mathbf{p}$} \\
\hline & \multicolumn{2}{|c|}{ Absence } & \multicolumn{2}{|c|}{ Presence } & \\
\hline & $\mathbf{N}$ & $\%$ & $\mathbf{N}$ & $\%$ & \\
\hline Patients using & 40 & 53.33 & $2 *$ & 8.33 & $<0.001$ \\
\hline Patients not using & 35 & 46.67 & 22 & 91.67 & \\
\hline Total & 75 & 100 & 24 & 100 & \\
\hline
\end{tabular}

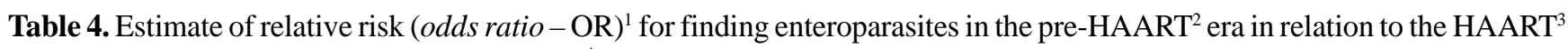
era in patients with HIV/AIDS seen at hospitals ${ }^{4}$ in Fortaleza-CE, Brazil

\begin{tabular}{lccr}
\hline \multirow{2}{*}{ Intestinal parasites } & $\begin{array}{c}\text { Estimate of } \\
\text { odds ratio (OR) }\end{array}$ & \multicolumn{2}{c}{$\mathbf{9 5 \% \text { confidence interval }}$} \\
\cline { 2 - 4 } & 5.605 & 3.416 & Upper limit \\
\hline Occurrence of any species & 7.774 & 1.872 & 9.197 \\
Hookworms & 3.481 & 1.807 & 32.286 \\
Strongyloides stercoralis & 9.029 & 2.179 & 6.708 \\
Ascaris lumbricoides & 14.885 & 2.040 & 37.411 \\
Trichuris trichiura & 8.473 & 1.150 & 108.630 \\
Giardia duodenalis & - & & 62.451 \\
Cryptosporidium sp. ${ }^{5}$ & - & \\
\hline 1-Considering the HAART era as "protective factor" against enteroparasitoses; 2 - Jan/1990 to Mar/1995; 3 - Sep/2005 to Jan/ \\
2007; 4-Hospital São José de Doenças Infecciosas and Hospital Universitário Walter Cantídio; 5 - It was not possible to estimate \\
the odds-ratio due to prevalence of zero percent in the HAART era.
\end{tabular}


In the HAART era, it was possible to obtain data on some clinical aspects of the patients to correlate with results of the FPE (Table 2). In this era (Endolimax nana, Iodamoeba butschlii), 62 patients (62\%) used antiretrovirals regularly for at least 15 days from the time of the FPE, where $30.7 \%$ of them utilized protease inhibitors. In this group, intestinal parasites were more often detected among patients who were on HAART around the time of FPE (35.1\%; 13/37), while the frequency of enteroparasites in patients on HAART was $17.5 \%(11 / 62)(p=0.058)$.

Gastrointestinal symptoms were reported by $49 \%$ of the patients of Group 2 (one to five symptoms) at the time of the interview and around the time of fecal specimen collection, with a predominance of diarrhea in $36 \%$ of them; however, there was no statistical significance between the occurrence of diarrhea and FPE positivity for enteroparasites $(p=0.626)$.

In the HAART era, CD4+ T lymphocyte counts allowed the identification of patients with acquired immunodeficiency syndrome (AIDS). A greater frequency of intestinal parasites was found among those with this condition, according to the criteria defining AIDS of Brazil's Ministry of Health (73.9\%) [19], as well as by the criteria of the Centers for Disease Control and Prevention in the USA (60.9\%) [20], where there was a difference of marginal significance $(p=0.08)$. With regard to viral load, there was no apparent relationship between viral RNA levels detectable or undetectable and the presence of enteroparasites $(p=0.318)$.
In Group 2, 53\% of the patients made prior use of some anti-infective medication up to one month before the FPE. The combination sulfamethoxazole + trimethoprim was the most used (75.5\%; 40/53), followed by the wide-spectrum antiparasitic agent albendazole (28.3\%; 15/53) and secnidazole (18.9\%; 10/53), a drug with antiprotozoal action. Table 3 shows the use of the antiparasitic medication in relation to the results of the FPE.

Considering the HAART era as a "protective factor" against intestinal parasitoses, we calculated the relative risk (odds ratio - OR) of the patients of the pre-HAART era for having enteric parasites in comparison with the HAART era, for the enteroparasites in which there was statistically significant reduction in prevalence in this era. We thereby showed at the $5 \%$ level of significance that patients of Group 1 (pre-HAART era) had a 5.6 times greater chance of contracting enteroparasites than those of the HAART era (Table 4).

\section{Discussion}

In the present study, the distribution of age varied significantly between the two eras $(\mathrm{p}<0.001)$, where patients were older in the HAART era, what can be attributed to the reduction in morbi-mortality and consequent increase in survival [21]. Also it was observed a reduction in the sex ratio between the two populations studied (from 4.74 to 3.55, men

Figure 1. Prevalence of enteroparasites in pre-HAART ${ }^{1}$ and HAART $^{2}$ eras in patients with HIV/AIDS seen at hospitals ${ }^{3}$ in Fortaleza-CE, Brazil.

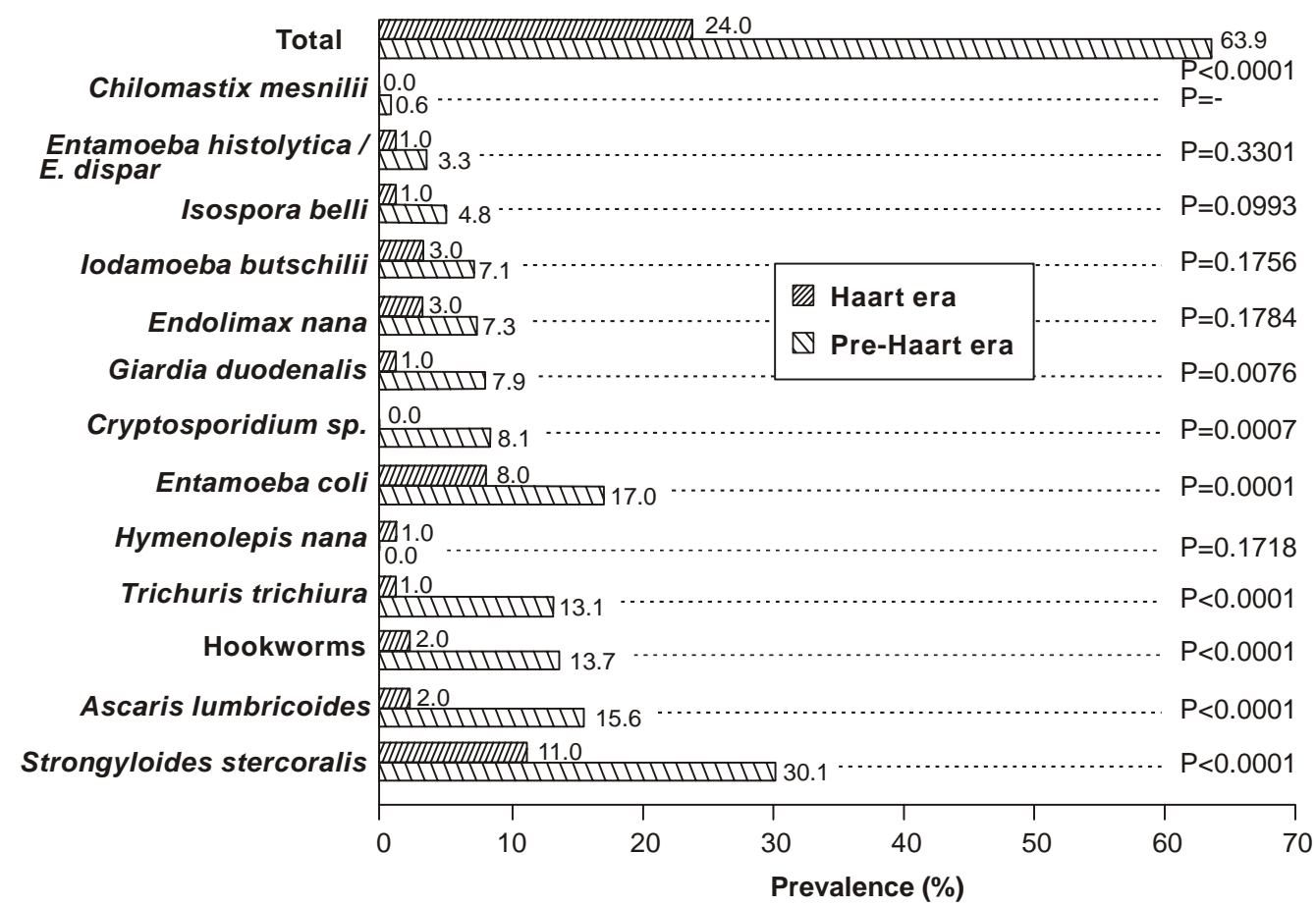

1 - Jan/1990 to Mar/1995; $n=482 ; 2$ - Sep/2005 to Jan/2007; n = 100; 3 - Hospital São José de Doenças Infecciosas and Hospital Universitário Walter Cantídio. 
to women), albeit not statistically significant $(p=0.32)$. In the state of Ceará, in Brazil, the current ratio of males to females is about 1.9 , very close to that observed for the whole country (1.5) [22], indicating a tendency toward the stabilization of the disease among men and spread of the epidemic among women. Currently, the AIDS epidemic, in Brazil, is characterized by a sexual transmission, involving $60 \%$ of the reported cases, with heterosexualization of HIV infection being notable since the 1990s [21]. Here, we observed this phenomenon in the current era. The transmission of the virus grew significantly among MSW and WSM (respectively, Group $1=12.66 \%$ and $14.73 \%$; Group $2=36 \%$ and 22\%; MSW: $\mathrm{p}<0.001$; WSM: $\mathrm{p}=0.074$ ). Still, we found that $40 \%$ of the cases of the HAART era are in categories MSM and MSWM (16\% and 24\%, respectively) (Table 2), a picture similar to that described by Dourado and et al. (2006), who pointed out that in Brazil, there was an occurrence of $42.9 \%$ of reports in the same categories, emphasizing the impact of unprotected sexual relations in the transmission of HIV [21].

With regard to the categories of exposure to the virus not linked to sex, it is seen that in the early stages of the epidemic in Brazil during the 1980s, there was an important contribution of the transfusion of blood and blood derivatives and of the use of injectable drugs [23]. Due to the introduction of efficient blood screening, the transmission of HIV by this route declined significantly in the country. However, the transmission of the virus among users of injectable drug (UID) who share syringes increased from $2 \%$ to $5 \%$, between 1984 and 1986, and up to $20 \%$ in 1990, staying at a level of $20 \%-25 \%$ in the large cities, characterizing parenteral transmission of HIV as an important route of viral dissemination in the country [24]. We found in this category (UID = 1.24 and $2 \%$ in the pre-HAART and HAART eras, respectively) data compatible with that described for the state of Ceará, in Northeast Brazil, where the use of injectable drugs does not assume the same proportions found in the large metropolises of the South and Southeast of Brazil [22,24].

The nematode $S$. stercoralis, the most prevalent parasite in this study in both eras, has been shown to be endemic in developing countries, where it is associated with situations that lead to immunodeficiency, including HIV infection [2529]. The life cycle of this helminth favors self-infection, with the possibility of hyperinfection and spreading, which are aggravated in conditions of immunosuppression [30]. The transformation of rhabditoid larvae into infective filarioid larvae, in the intestine of the carrier, could also favor interpersonal transmission of the parasite; these larvae present in the anorectal region of an individual, man or woman, could penetrate directly the penis of the partner during anal sexual intercourse. Thus, men would have a greater chance of being infected and/or reinfected by having sodomy relations with partners of both sexes [31,32]. Our data corroborate this supposition, since among 398 men evaluated in the preHAART era, 129 (32.41\%) had S. stercoralis, while among women the incidence was $19.04 \%$ (16/84), with high statistical significance $(p=0.018)$. In the HAART era this analysis could not be carried out in view of the fewer number of patients with FPE positive.

Cryptosporidium sp. was detected in $8.1 \%$ of the patients studied in the pre-HAART era, while it was not found in any of the patients in the HAART era, demonstrating the reduction in its prevalence between the two eras ( $p=0.0007)$. Wuhib et al. (1994), in a study conducted in Ceará in the pre-HAART era, detected a prevalence of $21.4 \%$ of cryptosporidiosis among patients with HIV/AIDS with diarrhea and 5\% in those without diarrhea [7]. A reduction in the prevalence of this opportunistic parasite has been observed in Brazil and around the world, even when the FPE includes specific staining methods, since the initial years of HAART use [33,34]. Nobre and et al. (2003), comparing the periods before and after the implementation of HAART, detected a prevalence of $2.8 \%$ and $1.1 \%$, respectively, a low occurrence in both eras, but still lower in the HAART era [14]. Cimerman and et al. (1999) had detected a prevalence of $24.44 \%$ of cryptosporidiosis among HIV-positive patients with diarrhea in São Paulo in the first years of HAART use [3], but in a more recent study, with HAART in full force, the prevalence of cryptosporidiosis was $6.8 \%$, being concentrated in patients with CD4+ T lymphocyte counts below 200 cells/ $\mathrm{mm}^{3}$ [11]. Kaminsky et al., in 2004, also observed the absence of Cryptosporidium sp. when evaluated 133 patients with HIV in Honduras [35], as in the study by Nwokediuko and et al. in 2002, who did not find this parasite among $161 \mathrm{HIV}$-positive patients in Nigeria [36]. The resolution of infections by Cryptosporidium sp. in patients with HIV/ AIDS has been attributed to the reconstitution of the immune system by HAART, even in patients without specific treatment for the parasite [34;37-40]. Moreover, there is evidence, in vivo as well as in vitro, that the control of cryptosporidiosis in patients on HAART are also helped by the anti-HIV protease inhibitors, which could be acting on the aspartylprotease of the parasites [41-43].

The occurrence of diarrhea in patients did not show a correlation with the presence of enteroparasites $(p=0.626)$ (Table 2). In their work in Ceará, Wuhib et al. (1994) detected diarrhea in 51\% of 166 patients evaluated, but without correlation with the presence of enteroparasites, with the exception of Cryptosporidium parvum $(\mathrm{p}<0.005)$ [7]. Considering that the "enteropathy of AIDS" is a clinical picture in which gastrointestinal alterations are observed, such as diarrhea, without being able to associate them to the presence of an enteropathogen, our data corroborate those in the literature, even though we limited our examination to protozoans and helminths, excluding other possible agents of enteric infections [44-51]. As in the occurrence of diarrhea, there was no statistical significance between detectable viral load and positive FPE ( $\mathrm{p}=0.318$ ) (Table 2$)$. In relation to the CD4+ T lymphocytes, a correlation of marginal significance was observed between low counts $\left(\leq 200\right.$ cells $\left./ \mathrm{mm}^{3}\right)$ and positive FPE ( $p=0.080)$, characterizing the greater occurrence of enteroparasites in patients in the AIDS phase, according to the CDC (USA) (Table 2) [20].

www.bjid.com.br 
The combination sulfamethoxazole + trimethoprim was the anti-infective medication most often employed in the HAART era. Such combination, prescribed usually as chemoprophylaxis or treatment of pneumocystosis, is active against Isospora belli, which could have contribute to the low prevalence of this coccidiosis detected in this era [52,53]. In a single case of isosporiasis found in Group 2, the patient had not used this medication around the time of the FPE. A low prevalence of Isospora belli has also been demonstrated by other authors who attribute the finding to the broad utilization of sulfamethoxazole + trimethoprim by the patients $[1,4,8]$. In evaluating the use of drugs that could exert an effect on enteroparasites, we observed that of the 75 patients with negative FPE, 40 (53.33\%) utilized medication with antihelminthic or antiprotozoal activity up to one month before the FPE, while among the 24 patients with positive FPE, only two utilized this type of medication, albeit at doses below those recommended; the difference was statistically significant $(\mathrm{p}<0.001)$ (Table 4$)$.

With the exception of $H$. nana, detected in only one patient of the HAART era, there was a significant reduction in the general prevalence of intestinal parasites between the preHAART and HAART eras $(\mathrm{p}<0.0001)$. This appears to represent a "protective factor" against acquiring enteroparasites, tending to reduce their prevalence by 5.6 times in this era. Various factors certainly contribute to this, such as: $i)$ the use of HAART, with improvement in immunologic conditions of the patients and better response to infections, including parasitic ones, or even with a direct action on certain enteroparasites [42;54-57]; ii) the utilization of chemoprophylaxis which can act on intestinal parasites, reducing their prevalence $[1,4,8,52,53]$; iii) better clinical handling of the patients, with constant updating of protocols for treatment and prophylaxis, besides their better follow-up through laboratorial tests; and iv) more conscientious actions by the patients themselves in adopting prevention and treatment measures against intestinal parasites.

In the current era, in comparison with the presence of enteroparasites in subgroups with and without use of HAART around the time of the FPE, we found a greater incidence in patients not on HAART ( $p=0.058$ ) (Table 2 ), confirming the protective role of HAART against these infections.

The institution of antiparasitic medication, also called "therapeutic package", which consists of the administration of an antihelminthic, such as albendazole, and an antiprotozoal, such as secnidazole, both in a single dose and sometimes complemented with sulfamethoxazole + trimethoprim, has been the current practice in Ceará, and in Brazil as well, without prior FPE. Such practice leads to treatment failures, principally with strongyloidiasis which needs to be treated with higher doses of albendazole, or even with the utilization of larvicidal medication, such as thiabendazole. Therefore, we recommend that the FPE, performed critically and including specific methods for studying intestinal coccidiosis and nematode larvae, besides the usual techniques, should be routinely utilized in the follow- up of patients with HIV/AIDS, with the purpose of optimizing the institution of treatment and of other preventive measures, aiming to obtain a better quality of life for these patients.

\section{Acknowledgments}

We thank especially Prof. Rosa Maria Salani Mota of the Department of Statistics and Applied Mathematics, Federal University of Ceará (UFC), for statistical analyses, the medical staff of HSJ and the clinicians of the Infectology Outpatient Clinic of HUWC, for providing patients for this study. The granting bodies Conselho Nacional de Desenvolvimento Científico and Tecnológico (CNPq) and Coordenação de Aperfeiçoamento de Pessoal de Nível Superior (CAPES) provided financial support through the Postgraduate Program in Pathology at UFC.

\section{References}

1. Arcoverde C., Magalhães V., Lima R.A., et al. Enteroparasitoses em pacientes infectados pelo vírus da imunodeficiência humana (HIV) atendidos no Hospital das Clínicas da UFPE. Revista Brasileira de Análises Clínicas 2004;36:13-7.

2. Arenas-Pinto A., Certad G., Ferrara G., et al. Association between parasitic intestinal infections and acute or chronic diarrhoea in HIV-infected patients in Caracas, Venezuela. Int J STD AIDS 2003; 14:487-92.

3. Cimerman S., Cimerman B., Lewi D.S. Enteric parasites and AIDS. São Paulo Med J/Rev Paul Med 1999;117:266-73.

4. Cimerman S., Cimerman B., Lewi D.S. Avaliação da relação entre parasitoses intestinais e fatores de risco para o HIV em pacientes com AIDS. Rev Soc Bras Med Trop 1999;32:181-5.

5. Gumbo T., Sarbah S., Gangaidzo I.T., et al. Intestinal parasites in patients with diarrhea and human immunodeficiency virus infection in Zimbabwe. AIDS 1999;13:819-21.

6. Moran P., Ramos F., Ramiro M., et al. Entamoeba histolytica and/ or Entamoeba dispar: infection frequency in HIV+/AIDS patients in Mexico City. Exp Parasitol 2005;110:331-4.

7. Wuhib T., Silva T.M., Newman R.D., et al. Cryptosporidial and microsporidial infections in human immunodeficiency virusinfected patients in northeastern Brazil. J Infect Dis 1994;170: 494-7.

8. Escobedo A.A., Núñez F.A. Prevalence of intestinal parasites in Cuban acquired immunodeficiency syndrome (AIDS) patients. Acta Trop 1999;72:125-30.

9. Garlipp C.R., Bottini P.V., Teixeira A.T.L.S. The relevance of laboratory diagnosis of human cryptosporidiosis and other coccidian. Rev Inst Med Trop S Paulo 1995;37:467-9.

10. Lindo J.E., Dubon J.M., Ager A.L., et al. Intestinal parasitic infections in human immunodeficiency virus (HIV)-positive and HIV-negative individuals in San Pedro Sula, Honduras. Am J Trop Med Hyg 1998;58:431-5.

11. Cimerman S., Castañeda C.G., Iuliano W.A., Palacios R. Perfil das enteroparasitoses diagnosticadas em pacientes com infecção pelo vírus HIV na era da terapia antiretroviral potente em um centro de referência em São Paulo, Brasil. Parasitol Latinoam 2002;57:111-9.

12. Peters C.S., Sable R., Janda W.M., et al. Prevalence of enteric parasites in homosexual patients attending an outpatient clinic. J Clin Microbiol 1986;24:684-5.

13. Keystone J.S., Keystone D.L., Proctor E.M. Intestinal parasitic infections in homosexual men: prevalence, symptoms and factors in transmission. Can Med Assoc J 1980;123:512-4.

14. Nobre V., Braga E., Rayes A., et al. Opportunistic infections in patients with AIDS admitted to a university hospital of the southeast of Brazil. Rev Inst Med Trop S Paulo 2003;45: 69-74. 
15. Palella F.J., Delaney K.M., Mooran A.C., et al. Declining morbidity and mortality among patients with advanced human immunodeficiency virus infection. N Engl J Med 1998;338:853-60.

16. Verheggen R. Immune restoration in patients with HIV infection: HAART and beyond. J Assoc Nurses AIDS Care 2003;14:76-82.

17. Willemot P., Klein M.B. Prevention of HIV-associated opportunistic infections and diseases in the age of highly active antiretroviral therapy. Expert Rev Anti Infect Ther 2004;2:521-32.

18. De Carli G.A. Parasitologia Clínica. São Paulo: Atheneu, 2001.

19. Brasil. Ministério da Saúde. Secretaria de Vigilância em Saúde. Programa Nacional de DST e AIDS. Critérios de definição de casos de AIDS em adultos e crianças. Brasília, DF. 2004.

20. CDC. 1993 revised classification system for HIV infection and expanded surveillance case definition for AIDS among adolescents and adults. MMWR, 41 (RR-17): 1-19, 1992.

21. Dourado I., Veras M.A.S., Barreira D., Brito A.M. Tendências da epidemia de Aids no Brasil após a terapia anti-retroviral. Rev Saúde Pública 2006;40:9-17.

22. Ceará. Secretaria de Saúde do Estado do Ceará. Coordenaria de Políticas em Saúde. Núcleo de Epidemiologia. Núcleo de Atenção à Saúde Reprodutiva e Sexual. Boletim Epidemiológico - DST/ AIDS, dez. 2006.

23. Castilho E.A., Chequer P., Szwarcwald C.L. A AIDS no Brasil. In: Rouquayrol M.Z.; Almeida Filho N. Epidemiologia \& Saúde. 5. ed. Rio de Janeiro: MEDSI, 1999.

24. Morgado M.G., Barcellos C., Pina M.F., Bastos F.I. Human immunodeficiency virus/acquired immunodeficiency syndrome and tropical diseases: a Brazilian perspective. Mem Inst Oswaldo Cruz 2000;95, suppl I: 145-51.

25. Feitosa G., Bandeira A.C., Sampaio D.P., et al. High prevalence of giardiasis and strongyloidiasis among HIV-infected patients in Bahia, Brazil. Braz J Infec Dis 2001;5: 339-44.

26. Gomez Morales M.A., Atzori C., Ludovisi A., et al. Opportunistic and non-opportunistic parasites in HIV-positive and negative patients with diarrhoea in Tanzania. Trop Med Parasitol 1995;46:109-14.

27. Keiser P.B., Nutman T.B. Strongyloides stercoralis in the immunocompromised population. Clin Microbiol Rev 2004;17: 208-17.

28. Pinlaor S., Mootsikapun P., Pinlaor P., et al. Detection of opportunistic and non-opportunistic intestinal parasites and liver flukes in HIV-positive and HIV-negative subjects. Southeast Asian J Trop Med Public Health 2005;36:841-5.

29. Zago-Gomes M.P., Aikawa K.F., Perazzio S.F., et al. Prevalence of intestinal nematodes in alcoholic patients. Rev Soc Bras Med Trop 2002;35:571-4.

30. Scull M.C.D., Castro O., Núñez F.Á., Capó V. Estrongiloidiosis diseminada en pacientes con SIDA: a propósito de 2 casos. Rev Cubana Med Trop 2006;58.

31. Chaves C.S., Vale J.M., Coêlho I.C.B., et al. Prevalência das enteroparasitoses intestinais em pacientes portadores de HIV/ AIDS. Jornal Brasileiro de DST 1996;8:36.

32. Dias R.M.D.S., Mangini A.C.S., Torres D.M.A.G.V., et al. Ocorrência de Strongyloides stercoralis em pacientes portadores da síndrome de imunodeficiência adquirida (AIDS). Rev Inst Med Trop S Paulo 1992;34:15-7.

33. Le Moing V., Bissuel F., Costagliola D., et al. Decreased prevalence of intestinal cryptosporidiosis in HIV-infected patients concomitant to the widespread use of protease inhibitors. AIDS 1998; $12: 1395-7$.

34. Maggi P., Larocca A.M., Quarto M., et al. Effect of antiretroviral therapy on cryptosporidiosis and microsporidiosis in patients infected with human immunodeficiency virus type 1. Eur J Clin Microbiol Infect Dis 2000;19:213-7.

35. Kaminsky R.G., Soto R.J., Campa A., Baum M.K. Intestinal parasitic infections and eosinophilia in an human immunodeficiency virus positive population in Honduras. Mem Inst Oswaldo Cruz 2004;99:773-8.
36. Nwokediuko S.C., Bojuwoye B.J., Onyenekwe B. Apparent rarity of cryptosporidiosis in human immunodeficiency virus (HIV)related diarrhea in Enugu, south-Eastern, Nigeria. Nig Postgran Med J 2002;9:70-3.

37. Carr A., Marriot D., Field A., et al. Treatment of HIV-1-asociated microsporidiosis and cryptosporidiosis with combination antiretroviral therapy. Lancet 1998;351:256-61.

38. Miao Y.M., Awad-el-Kariem F.M., Franzen C., et al. Eradication of cryptosporidia and microsporidia following successful antiretroviral therapy. J Acquir Immune Defic Syndr 2000;25:124-9.

39. Oldfield E.C. Evaluation of chronic diarrhea in patients with human immunodeficiency virus infection. Rev Gastroenterol Disord 2002;2:176-88.

40. Schmidt W., Wahnschaffe U., Schafer M., et al. Rapid increase of mucosal CD4 $\mathrm{T}$ cells followed by clearance of intestinal cryptosporidiosis in na AIDS patient receiving highly active antiretroviral therapy. Gastroenterology 2001;120: 984-7.

41. Gomez Morales M.A. La highly active antiretroviral therapy e la criptosporidiosi. Parassitologia 2004;46:95-9.

42. Pozio E. La Highly Active Antiretrovrial Therapy e le infezioni protozoarie opportuniste. Parassitologia 2004;46:89-93.

43. Pozio E., Gomez Morales M.A. The impact of HIV-protease inhibitors on opportunistic parasites. Trends Parasitol 2005;21:58-63.

44. Attili S.V.S., Gulati A.K., Singh V.P., et al. Diarrhea, CD4 counts and enteric infections in a hospital - based cohort of HIVinfected patients around Varanasi, India. BMC Infect Dis 2006;6.

45. Brantley R.K., Williams K.R., Silva T.M.J., et al. AIDS-associated diarrhea and wasting in Northeast Brazil is associated with subtherapeutic plasma levels of antiretroviral medications and with both bovine and human subtypes of Cryptosporidium parvum. Braz J Infec Dis 2003;7:16-22.

46. Castello-Branco L.R.R., Lewis D.J.M., Ortigão-de-Sampaio M.B. Griffin G.E. Gastrointestinal immune response in HIV infected subjects. Mem Inst Oswaldo Cruz 1996;91:363-6.

47. Clayton F., Kotler D.P., Kuwada S.K., et al. Gp 120-induced Bob/ GPR15 activation - A possible cause of human immunodeficiency virus enteropathy. Am J Pathol 2001;159:1933-9.

48. Heise C., Dandekar, S., Kumar P., et al. Human immunodeficiency virus infection of enterocytes and mononuclear cells in human jejunal mucosa. Gastronterology 1991;100:1521-7.

49. Kelly P., Davies S.E., Mandanda B. et al. Enteropathy in Zambians with HIV related diarrhea: regression modeling of potential determinants of mucosal damage. Gut 1997;41:811-6.

50. Kotler D.P., Gaetz H.P., Lange M., et al. Enteropathy associated with the acquired immunodeficiency syndrome. Ann Inter Med 1984; $101: 421-8$.

51. Nannini E.C., Okhuysen P.C. HIV1 and the gut in the era of highly active antiretroviral therapy. Curr Gastroenterol Rep 2002;4:392-8.

52. Lindsay D.S., Dubey J.P., Blagburn B.L. Biology of Isospora spp. From humans, nonhuman primates, and domestic animals. Clin Microbiol Rev 1997;10: 19-34.

53. Patel N., Koziel H. Pneumocysts jiroveci pneumonia in adult patients with AIDS: treatment strategies and emerging challenges to antimicrobial therapy. Treat Resp Med 2004;3:381-97.

54. Autran B., Carcelaint G., Li T.S., et al. Restoration of the immune system with anti-retroviral therapy. Immunol Lett 1999;66:207-11.

55. Grube H., Ramratnam B., Ley C., Flaningan T.P. Resolution of AIDS associated cryptosporidiosis after treatment with indinavir. Am J Gastroenterol 1997;92:726.

56. Hommer V., Eichholz J., Petry F. Effect of antiretroviral protease inhibitors alone, and in combination with paromomycin, on the excystation, invasion and in vitro development of Cryptosporidium parvum. J Antimicrob Chemoter 2003;52:359-64.

57. Mele R., Gomez Morales M.A., Tosini F., Pozio E. Indinavir reduces Cryptosporidium parvum infection in both in vitro and in vivo models. Int J Parasitol 2003;33:757-64. 